\title{
Knowledge Management: A review of the field and of OR's contribution
}

John S. Edwards, Bashar Ababneh, Matthew Hall* and Duncan Shaw, Aston University

(*- corresponding author: m.j.hall@aston.ac.uk, Dr Matthew Hall, Operations and Information Management, Aston Business School, Aston University, Aston Triangle, Birmingham, B4 7ET, U.K.)

\begin{abstract}
This paper examines the field of Knowledge Management (KM) and identifies the role of Operational Research (OR) in key milestones and in KM's future. With the presence of the OR Society journal Knowledge Management Research and Practice and with the INFORMS journal Organization Science, OR may be assumed to have an explicit and a leading role in KM. Unfortunately, the origins and the evidence of recent research efforts do not fully support this assumption. We argue that whilst OR has been inside many of the milestones there is no explicit recognition of its role and while OR research on KM has considerably increased in the last 5 years it still forms a rather modest explicit contribution to KM research. Nevertheless, the depth of OR's experience in decision-making models and decision support systems, soft systems with hard systems, and in risk management suggest that OR is uniquely placed to lead future KM developments. We suggest that a limiting aspect of whether OR will be seen to have a significant profile will be the extent to which developments are recognized as being informed by OR.
\end{abstract}

Key words: knowledge management, operational research; organisational learning, intellectual capital.

\section{Introduction}

Knowledge management (KM) is a term that was coined less than thirty years ago, even though it refers to a set of activities that must have been occupying the minds of humans for millennia. How to make use of what we know? How to find out what others know? How to come up with new ideas? These are just a few of the facets of what has become known as knowledge management. As will become clear, this apparent contradiction of having a new term for a very long-standing phenomenon is typical of the somewhat tangled, fuzzy picture that knowledge management presents. Therefore, in reviewing the past, present and future of knowledge management, and its relationship to operational research, it will sometimes be difficult to work in terms of precise milestones and landmarks. Rather, we will often be able to give no more than indications of changes of direction or new developments.

The fuzziness raises its head as soon as we attempt to define knowledge management. There is no common agreed definition. For the purposes of this review, we will define knowledge management (KM) as "supporting and achieving the creation, sharing, retention, refinement and use of knowledge (generally in an organizational context)". The relationship between these activities, which may be seen as a knowledge management life-cycle, is shown in Figure 1. 


\section{$<$ FIGURE 1 ABOUT HERE $>$}

This definition leads naturally to a further question of definition: what is knowledge? This is a very difficult question indeed to answer: for example, Mingers (2008) lists 13 different senses of the verb "I know". We will not attempt to define knowledge here, but instead, again for the purposes of this review, adopt the pragmatic viewpoint that if someone claims to be writing about knowledge then we accept their claim.

The structure of the paper is as follows. We begin by reviewing the history of KM, which also involves diversions into its pre-history: those disciplines that led to knowledge management, but were not called KM at the time. We go on to look at the contributions of OR and the OR community to knowledge management, including a bibliometric analysis of KM papers in OR journals. We then offer some observations about future directions for KM, especially those that we believe may be most fruitful for OR.

\section{The history of knowledge management}

It is typical of any academic discourse in the business and management field that research and scholarship follow in the wake of new business and management practices: Theory follows practice more than practice follows theory. In the case of knowledge management, the first evidence that businesses were paying attention to the need to manage knowledge came in the 1980s, but it is not until the 1990s that the first academic papers and conferences were starting to comment and theorise upon this interesting new phenomenon. The explosion of interest in KM caused some to question whether this was simply a passing fad (e.g. Quintas et al, 1997) or seek to explain its emergence in terms of the waxing and waning of management fashion (e.g. Scarborough and Swan, 2001). However, we argue that the term 'KM' has become the enduring label for a history of inter-related phenomena which represent not a passing phase, but a fundamental shift in the structure of global economic organization. This section therefore raises two key questions in turn: First, why has knowledge and the need to manage knowledge become an object of management attention? Second, what is the genealogy of knowledge management as an academic discourse? These two questions cannot always be so conveniently separated, as it is often academic publications where the observations of new business and management practices are made.

\section{Knowledge as an object of management attention}

In the US several large organizations were making explicit efforts to capitalise on their knowledge before the term 'knowledge management' was reputedly first coined by Karl Wiig in 1986 at a keynote address for the International Labour Organization entitled 'Management of knowledge: Perspectives for a new opportunity' (Beckman, 1999). According to Wiig (1997b) the earliest documented success of a corporation adopting a knowledge-focus to its management practice was Chaparral Steel, which was later written about by Leonard-Barton (1995). This is unusual for a manufacturing company, as most subsequent examples of organisations cited as milestones in the history of KM might be considered information- or knowledgeintensive industries: Both Wiig (1997b) and Boisot (1998) highlight the Digital 
Equipment Corporation (DEC) as a significant milestone in the development of its XCON expert system. By the late 1980s most of the large management consulting firms had begun to integrate knowledge management into their business strategy, and to offer KM in their portfolio of consultancy offerings. In 1991 the Swedish insurance company Skandia appointed Leif Edvinsson as the first Director of Intellectual Capital, a position now institutionalised in many corporations as the Chief Knowledge Officer (CKO).

Many writers point out that knowledge and knowledge processes have always been important to organisations and their managers. Quintas (2002) quotes the economist Alfred Marshall who made the claim as early as 1890 that "knowledge is our most powerful engine of production." The question is therefore raised, why did the management of knowledge only start to become such an important focus to organisations in the 1980s and 1990s?

A number of related factors have together conflated the arrival of KM as a focus of organisational attention. Most prominent among these factors is the belief that we are now in the era of the 'knowledge economy' in which an increasing proportion of wealth is generated by organisations which have few tangible assets, and in which 'knowledge-intensive' organisations (Starbuck, 1992) need to compete increasingly on their ability to configure and manage knowledge. Earliest evidence of the arrival of the knowledge economy is often attributed to Machlup (1962) who conducted an extensive study of structural changes in the post-war US economy and examined the rise in 'knowledge production.' At a similar time Drucker (1969) was beginning to popularise the notion of a changing society and the birth of a new type of organisation populated by 'knowledge workers.' For contemporary knowledge management writers, the seminal work is Bell's forecasting of the end of the industrial era and the arrival of the 'post-industrial' society in which knowledge and information play a qualitatively different and more important role (Bell, 1974).

Another prominent and closely-related factor is the rise of the so-called 'information society' in which the convergence of information and communication technologies (ICT) is transforming the means of production and facilitating globalisation. With the launch in 1969 of ARPANET, widely seen as the precursor to the World Wide Web, it is no coincidence that a new 'techno-economic paradigm' based on ICT (Freeman and Perez, 1988) is inextricably linked with conceptions of a post-industrial society. For Castells (1996, p.17) 'informationalism' is the new mode of production, where productivity lies in the "technology of knowledge generation, information processing and symbolic communication.” Thus technology has facilitated the emergence of new forms of work and organisation in global supply chains and networked multi-national corporations (Newell et al., 2002). For modern companies the evolution of technology in one sense has facilitated the potential to configure knowledge in novel ways, and in another sense has precipitated the imperative to manage knowledge more effectively: For Quintas (Quintas, 2002) the need to innovate more quickly as the economy gathers pace, and the importance of sharing knowledge across organisational boundaries, are imperatives of knowledge management in a global network society. As well as the information and communication potential of new technology, advances in knowledge-based systems and artificial intelligence have also enabled businesses to model and support organisational knowledge processes, for example in groupware 
and collaborative work, decision-support systems and advanced search engines (Shadbolt et al., 1999).

\section{KM as an academic discourse}

Sveiby and Lloyd's book on managing know-how (Sveiby et al., 1987) is said to be the first published academic work to apply the term 'management' to 'knowledge.' However it was not until the late 1990s that Knowledge Management as an academic discourse seriously gathered momentum. This is graphically illustrated by Swan (1999), where an analysis of references to 'Knowledge Management' in a leading index of management-related journals shows more made in the first six months of 1998 than cumulatively in the previous five years. This is not to say that discourses around the themes of knowledge discussed in the previous section did not exist before this point. As we shall see in this section, the KM discourse represents a confluence of several academic disciplines - incorporating organisational behaviour, human resource management, computer science, information management, accountancy, and more - which collectively have converged on this predominantly practitioner-led phenomenon of knowledge as a focus for management attention. In this section we shall review the key academic strands which pre-configured the KM discourse. These are organisational learning, business process reengineering, expert systems/ artificial intelligence, and latterly, the resource-based (later the knowledge-based) view of the firm, which was the field within which the notion that knowledge can be managed firmly took hold. We shall then go on to see how the KM discourse diverged, leading to a so-called $2^{\text {nd }}$ generation of $\mathrm{KM}$.

\section{Organisational learning}

Before the conflation of the KM phenomenon, the importance of knowledge in organisations was already receiving considerable attention in the literature on learning in organisations. For example, Schön (1995) describes organisations as "repositories of cumulatively built up knowledge" and draws attention to managerial learning in an organisational context. Taking their lead from metaphors of organisations as 'brains' (Morgan, 1986), some have been developing the idea that organisations themselves can learn (e.g. (Senge, 1990)). Although Senge's 'fifth discipline' is a hard-systems approach, the other four disciplines - namely personal mastery, mental models, shared vision and team learning - essentially render this a soft systems approach (Panagiotidis et al., 2001).

Although in the past, research in learning was dominated by a cognitive and mental view of learning processes, more recently sociologists and psychologists have turned their attention to the social and cultural conditions in which learning occurs, of which the organisational context is a significant realm. Organisations are networks of social relations and systems of meaning through which knowledge in the workplace is learned (Wenger, 1998) . The literature on situated learning (Lave et al., 1991) and Mode 2 knowledge production (Gibbons et al., 1994) argues that learning in the workplace takes place more in the context of practice, than upon the receipt of abstracted and decontextualised information. Similarly Brown and Duguid (1991) observe that the work people actually do is different from the 'canonical practices' enshrined in company manuals and job descriptions. For Blackler (1995) practicebased theories of knowing are more useful than the objectification of 'knowledge' as a focus of management activity, "to avoid treating individuals as if they can be 
understood in isolation from their contexts, and the contexts as if they exist in isolation from individuals" (Blackler et al., 2000). The concept of 'communities of practice' stems from research into situated learning in the organisation (Brown et al., 1989; Lave et al., 1991).

\section{Business process reengineering}

The movement that became known as business process reengineering (BPR) came into being in a relatively short space of time at the beginning of the 1990s. At that time, many managers seemed to feel a sense of dissatisfaction: businesses were facing ever-increasing competitive pressures, Western managers in particular worried that they were losing out to other countries (such as the Asian Tiger economies), and the "old ways" no longer seem to be effective. As a result, it seemed that drastic action was called for.

Two papers appeared in quick succession in top American business journals (Davenport et al., 1990; Hammer, 1990), describing some "drastic actions" that organisations (mainly American) had taken. Contrary to what was widely perceived at the time, neither claimed to have invented the concept of BPR. Rather, they were trying to produce frameworks to describe and generalise what some companies had already been doing. There were four common elements in these actions:

- Radical change (as in the title of Hammer's paper “Don’t automate, obliterate!”)

- Emphasis on process

- Exploiting information technology (IT) to the full

- "Going back to the drawing board"

This attitude that nothing was taken for granted made an immediate impression, and each of the two "schools" then produced a book (Davenport, 1993; Hammer et al., 1993). Hammer and Champy's was a runaway best-seller, thus creating a great deal of popular interest and winning the "name" battle for the activity to be called business process reengineering.

Business process reengineering turned into a classic business "fad", with a strong backlash against it. Davenport's own analysis of what went wrong sums it up very well (Davenport, 1995). He describes "reengineering fever" as leading first to too much emphasis on technology at the expense of people, and then to too much emphasis on cost reduction (to pay for the technology and the consultants' fees). As Davenport puts it: "If you call massive layoffs re-engineering, people will not want to 'be re-engineered"”.

However, as the BPR movement collapsed, so knowledge management arose, and there were and are clear links between the two. These include the realisation of the importance of knowledge for organisations, an emphasis on process thinking, the need to balance people, process and technology views, and not least the continuing presence of Tom Davenport. Two ideas in particular, the use of IT to change how work is done, not just for greater efficiency, and stepping back to think with a "blank sheet of paper”, have great resonance with OR approaches.

\section{Expert systems/ Artificial intelligence/ knowledge engineering}


Another of the precursors of knowledge management, although curiously it is seldom acknowledged as such, comes from work within the field of artificial intelligence on expert/knowledge-based systems, and especially the work on knowledge engineering, i.e. the development of knowledge-based systems. The connection to knowledge management is evident in the word knowledge, but goes much deeper. The study of artificial intelligence "the science of making machines do things that would require intelligence if done by men (sic)" (Minsky, 1968) dates back to the 1950s, and work on expert systems - systems displaying a high level of expertise in a narrow domain began in the 1960s. The phrase knowledge-based systems later came to be preferred by many to the more pretentious expert systems, but both phrases are still in common use. Seen through a KM lens, expert/knowledge-based systems represent the first sustained attempt to codify knowledge using information technology. Thirty years of experience in developing them has also given rise to a great deal of understanding of the processes of trying to codify knowledge, which in KBS terms would be called processes of knowledge acquisition.

Indeed, Karl Wiig was working on expert systems at the time he coined the term knowledge management, and the short final section of his book on expert systems (Wiig, 1990) is one of the earliest publications of any kind on knowledge management. Similarly, the bread-making example discussed by Nonaka and Takeuchi (1995) would be seen as a typical AI example by those in that area. This involved the attempts by the Japanese company Matsushita to develop a home breadmaking machine. Only when one of the software engineers effectively apprenticed herself to a master baker to learn how it was done was the task successfully accomplished. AI specialists would see this as an example of the role of the knowledge engineer.

The two main avenues used in codification in expert/knowledge-based systems are knowledge elicitation from human experts, and machine learning. The latter has led to the field of data mining, while the legacy of the former in the shape of rule-based systems/routines is now commonplace, as anyone who has used software with a "wizard" will testify. However, the implications of the knowledge elicitation work on tacit, implicit and explicit knowledge seem to have been largely overlooked.

\section{Resource-based view of the firm}

The notion that knowledge can and should be managed emerges most obviously among those who advocate a resource-based view of the firm, which was first developed by Grant (1991). Grant subsequently discussed the centrality of knowledge to the resource-based theory (Grant, 1996; Grant, 1997). Although resource-based theory does not necessarily render knowledge a direct object of management, according to Spender (1996), those who take this view of the firm tend to seek ways in which knowledge is a "transferable, objective commodity" and subject to codification. This treatment of knowledge is also evident in the discourse around 'intellectual capital' (Edvinsson et al., 1996; Wiig, 1997a), with managers seeking to measure and control the intellectual value of their organisations. Although Nonaka was not necessarily an advocate of the resource-based view, his influential theory of organisational knowledge creation (Nonaka, 1994; Nonaka et al., 1995) was 
instrumental in popularising the notion that knowledge needs to be made explicit in order to be managed, and has become a central tenet among those who advocate the resource-based view.

\section{From $1^{\text {st }}$ generation to $2^{\text {nd }}$ generation $\mathrm{KM}$}

According to Roos and Von Krogh (1996), Sveiby (1996), Quintas et al (1997), Alvesson and Karreman (2001) and Scarbrough and Swan (2001), the early KM discourse therefore evolved around two perspectives on knowledge. One perspective treats knowledge as a reifiable object, capable of being packaged up, owned and passed around, characterised as the 'cognitive' (Swan et al., 1999) or 'cognitivist' (Von Krogh, 1998) perspective. Another perspective treats knowledge - or more significantly 'knowing' (Blackler, 1995) - as a human process which occurs between people in social networks, characterised by Swan et al. (1999) as the 'community' perspective. A similar distinction is made by Cook and Brown (1999) - although not in the context of knowledge management - between an 'epistemology of possession' where "what is known is typically treated as something people possess," and an 'epistemology of practice' which takes 'knowing' as its focus.

According to Hansen et al (1999), these approaches become manifest in two broad strategies for knowledge management: 'Codification', where the emphasis is on the relationship between people and documents - the advice for a company following a codification strategy is to "develop an electronic document system that codifies, stores, disseminates and allows re-use of knowledge." The alternative strategy is 'personalization', where the emphasis is on the relationship between people - the advice here is to "develop networks for linking people so that tacit knowledge can be shared.”

Thus in the early days, KM practice was dominated by an emphasis on codifiable information and investment in technology for knowledge capture and storage.

Recognising the limitations of an information-centric approach which characterised the so-called 'first generation' of KM initiatives, the discourse shifted to how people know and learn in the workplace, with a greater practical emphasis on how to encourage people to generate and share knowledge in organisational and social networks. Information and communication technology still plays a role, but in the second generation of KM practice the emphasis has now moved to the use of so-called 'web 2.0' tools to support an organic and less managerial approach to social participation in KM.

\section{$K M$ in practice}

A practitioner perspective on the development of $\mathrm{KM}$ is provided by the results of the MAKE awards (Most Admired Knowledge Enterprises). These have been decided as part of a research study carried out annually by Teleos, a research company specialising in KM and intellectual capital, in association with the KNOW network, beginning in 1998. They are based on a survey of practitioners, covering the Fortune 500 companies and Chief Knowledge Officers of other organisations regarded as being "expert" practitioners. Respondents are asked to nominate companies and then rate them on eight attributes:

- creating an enterprise knowledge-driven culture

- developing knowledge workers through senior management leadership 
- developing and delivering knowledge-based products/solutions

- maximizing enterprise intellectual capital

- creating an environment for collaborative knowledge sharing

- creating a learning organisation

- delivering value based on customer knowledge

- transforming enterprise knowledge into shareholder/stakeholder value

Lists are then compiled of those nominated, "finalists" (typically the top 50), the Top 20 and the overall winners, together with the leaders in particular business sectors and geographical regions. Table 1 shows the Top 20 in 1998 and in 2007.

\section{$<$ TABLE 1 ABOUT HERE $>$}

The 1998 list serves as an aide memoire of companies that were seen as pioneers in knowledge management and/or intellectual capital: all of those in the Top 20 were either pioneer users of KM, or pioneers in providing KM software and systems for others. It is strongly biased towards companies with headquarters in the USA (16 out of 20), and the only other region represented is Europe.

By contrast, the 2007 list shows more of an emphasis on companies whose business is providing information/knowledge (the BBC, Google, Wikipedia and perhaps Microsoft) and has much more of a global spread, including four companies based in Asia and four regarded as having "global management structures". For more detail on the 2007 study, see (Chase, 2007). Three companies (Accenture/Andersen Consulting, Ernst \& Young, and Microsoft) have won awards in all ten years so far.

Although a "snapshot" comparison, the above differences are indicative of the trends in the more detailed study. There has also been an increase in the diversity of the business sectors of the nominated companies. In 1998, almost all the nominated companies came from just six sectors: chemicals, computers, electronics and electrical equipment, oil and gas, pharmaceuticals and professional services, whereas in 2007 some 20 sectors are represented. The most crucial factors in winning the awards for the Top 20 companies in 2007 were success in maximizing enterprise intellectual capital and transforming enterprise knowledge into shareholder/stakeholder value.

These trends can be taken as representative of the state of KM in practice more generally in larger organisations. The nature of the study means that SMEs will not appear in the MAKE awards lists, and indeed there is evidence that the KM needs of SMEs are substantially different from those of larger organisations (Chen et al., 2006; Nunes et al., 2006; Sparrow, 2005).

\section{$\mathrm{KM}$ and the OR community}

Where is OR and Management Science (MS) in all of this? As with some other fields of endeavour, there are many OR influences and connections throughout the development of KM, if one knows where to look for them, but conversely OR is not the first area that leaps into the minds of non-OR people when thinking about the disciplines that have been involved in the rise of KM. 
Many OR methodologies support the managing of information and knowledge, but the body of OR that most closely aligns with the view of KM as a social process is problem structuring methods (PSMs). PSMs aim to help individuals and/or groups of stakeholders to understand highly complex situations that are characterized by multiple stakeholders with valid but competing views of issue; the need for discussion and negotiation of what is the purpose of addressing issue; personal learning about the legitimacy of alternative views to support making progress; building further insights using modelling techniques to structure the complexity of alternative interpretations (Pidd, 2003).

Using OR modelling to analyse available views (dare we say 'knowledge'?), PSM users may come to realize more about the systemic elements of the problem such that agree- able plans for addressing the situation can be developed, and later implemented. The authoritative volume edited by Rosenhead (1989) and updated by Rosenhead and Mingers (2001) includes the 'big three' PSMs of Soft Systems Methodology (Checkland and Scholes, 1999), Strategic Options Development and Analysis/Journey Making (Eden and Ackermann, 1998) and Strategic Choice (Friend and Hickling, 2005). Other less well-known PSMs include Visioning Choices (O’Brien and Meadows, 2007) and General Morphological Analysis (Ritchey, 2006).

When exploring PSMs and KM, Montibeller et al (2006) identify three aspects of PSMs: modelling support, using formal modelling techniques that underpin the PSM; facilitator support, someone to lead those involved through the use of the PSM; a methodology of facilitation, to ensure the group analyses the issues rigorously and in an appropriate theoretical manner. A central theme of the modelling support is often to produce explicit representations of how individuals/groups view a situation. The process, and the representations they create, helps those involved to: share knowledge through recording their views and making those available for others to absorb; organize knowledge by structuring the views into comprehensible representations; acquire knowledge from what others have shared; create knowledge by synthesizing competing views; use knowledge by explicitly relating the resulting PSM outcome to the representation. Thus, this process articulates (makes explicit) some of the knowledge that is believed to be relevant and records it as a group memory. The facilitator and methodology aspects also support the indirect sharing of knowledge between stakeholders for example, through facilitation techniques and the use of paper/computer-supported knowledge capturing (Montibeller et al, 2006).

The apparently strong affinity between PSMs and KM does feed through to KM research, especially by those in the OR KM community (Sutton, 2001; Coakes et al, 2002; Edwards et al, 2005; Shaw and Edwards, 2005). However, beyond the OR community PSMs appear to have had little influence on KM as a field.

OR's explicit impact may be best seen through the INFORMS journal, Organization Science, which precipitated the knowledge management discourse with Nonaka's seminal paper in which he proposes his 'dynamic theory of organizational knowledge creation’ (Nonaka, 1994). Davenport started out as an industrial engineer, which most 
OR people in Europe at least would classify as coming within the boundaries of OR/MS.

OR/MS people have made key contributions to KM or its antecedents. These include Herbert Simon's involvement in the development of artificial intelligence (Simon, 1969), George Huber's work on organisational learning (Huber, 1991), and the involvement of many OR people in the socio-technical systems movement.

One particular area where OR/MS people have been active is in the production of encyclopaedias and journals. Clyde Holsapple edited the Handbook on KM (Holsapple, 2003), which is arguably KM's first encyclopaedia. Elayne Coakes and Steve Clarke edited the Encyclopedia of Communities of Practice in Information and Knowledge Management (Coakes et al., 2006). Meanwhile in 2003 John Edwards became the founding editor of the OR Society's dedicated KM journal, Knowledge Management Research \& Practice (KMRP).

In terms of a timeline, OR interest in KM appeared to take off at the end of the 1990s. Table 2 shows some of the "firsts" in KM related to OR. These include the earliest conference streams and special issues in OR and KM, as well as the publications mentioned above.

\section{<INSERT TABLE 2 ABOUT HERE $>$}

In the next section we look at how the general OR community has contributed to KM development, including carrying out a bibliometric analysis.

\section{$K M$ in the OR literature}

\section{Preparing the articles set for analysis}

The searches carried out were based on Thomson ISI's Web of Knowledge, since it includes all the major OR/MS journals. A simple search on Web of Knowledge using the phrase "Knowledge Management" as topic criterion returned 6681 hits. This was then refined by choosing articles appearing in OR/MS journals, which reduced the total to 62 articles. We aimed to use a definition of "OR contribution to KM" that was sufficiently tight to satisfy those outside the field. This was: (1) the journal includes OR or MS in its title; or (2) the journal is published by an OR group or society.

Our original search had two limitations. Firstly, it missed several articles that we knew to be there, because KM articles do not always use "knowledge management" as a key word or topic term. A "knowledge process" search was carried using the following knowledge processes: creation, acquisition, sharing, transfer, use, refinement, codification, retention, and storage. After narrowing down the results to OR/MS journals 134 results were obtained, interestingly when comparing the two sets of results only 13 articles appeared in both searches. This lack of overlap suggests one reason for the lack of awareness of other KM research that has often been criticised: for example, Nonaka sees his research as on knowledge creation, not KM.

The second limitation of this approach is that the Web of Knowledge category of OR/MS journals does not include all OR journals about knowledge management. 
Organization Science, which is an INFORMS journal and carries a considerable amount of KM research, is listed in a different category, while Web of Knowledge does not yet list any specialised knowledge management journals at all, among them $K M R P$. We therefore added a separate search to ensure that all KM articles from Organization Science were included, using the same two searches as above. "Knowledge Management" as a search string returned 13 results, and the list of knowledge processes returned 28 results. In accordance with the previous results, only 3 results appeared in both sets. Finally, all the articles from KMRP (101 in total, from 2003 up to 2007) were included in the dataset. Thus a total of 322 articles were complied. Finally, for comparability, the time frame for articles was established as between 1990 and 2007, reducing the number of articles to 292.

\section{$<$ FIGURE 2 ABOUT HERE $>$}

Figure 2 represents the resulting articles in the dataset, presented on a time line. The first thing to notice is the difference before and after 2003, which seems less surprising bearing in mind that KMRP was first published in July 2003. However, the number of articles in KMRP published in 2003 was only 11, which does not fully explain the jump from 16 (in 2002) to 48 (in 2003). The other reason that helps explain this variation is special issues: one of Management Science and two in the same year from JORS. To sum up, the launch of KMRP along with three special issues expresses the strong attention paid to KM in 2003 within the OR community, which explains the sudden rise in KM articles in OR journals.

\section{KM articles and their KM focus.}

In this section we turn our focus to the different KM perspectives that are covered in this article dataset. This is done by using the categorisation of KM perspectives from the editorial paper in the first issue of KMRP (Edwards et al., 2003): business strategy, competitive advantage, innovation culture, leadership, organisational learning, intellectual capital, practices of KM, KM processes, social capital and networking (communities of practice), technology, and theories about knowledge. Moreover, two categories were added: performance and decision making. The articles are analysed in two groups: one has KM related articles from OR journals, while the latter represents articles from KMRP, as an OR sub-community.

\section{$<$ FIGURE 3 ABOUT HERE $>$}

The results for OR journals in general are shown in Figure 3. Knowledge Management processes have topped the chart, indicating an implicit agreement on the significance of processes. At this stage, it is arguably not justified to claim that KM processes are the most researched category because OR articles may come from different perspectives. Thus, OR articles might have a slightly different opinion on what KM means. For instance, Basu (1998), in possibly the first paper with the keyword "knowledge management" published in an OR journal, examined OR in Knowledge Management. Firstly, he describes how what he calls KM evolved from three computer science research streams, namely AI, database systems, and distributed computing. This explains why he used the terms knowledge-based systems and Knowledge Management interchangeably. Then, he continues to explain KM processes from that perspective, including knowledge capture and processing. So, if 
Basu's view is taken as more generally valid at the time, the processes that received top hits in Figure 3 might be explained by the fact that OR research was focusing on this area as it was the only known topic related to KM for OR: this goes with the fact that nearly all of the early-mid 1990s articles had focused one or more of the three top categories (processes, technology, and decision making).

Having explained the apparent OR focus in this period, it is easier to understand the logic for rating technology and decision making, second and third respectively. Such a position has implied that researchers were focusing on information and communication technologies that enabled organisations to make knowledge informed decisions, placing more hits for both categories. However, this attitude started to change at the turn of the century as more research started targeting other categories such as culture, leadership, and organisational learning placing it in fourth place with business strategy, competitive advantage, and innovation in fifth place.

\section{$<$ FIGURE 4 ABOUT HERE $>$}

Figure 4 shows the knowledge management community's cumulative view on KM research categories, as represented by KMRP. Interestingly, they do share the same number one focus with the general OR area, KM processes. However, are the reasons behind this focus similar? This question has prompted us to do a second level of analysis into the KM processes being researched in both communities (KMRP and the general OR) which will be explained in the following section.

The similarities between the communities' two foci end at this point, as more emphasis was placed on cultural, leadership, and organisation learning. This highlights the contextual nature of knowledge (Coakes, 2007; Jyrämä et al., 2007; Klein et al., 2007; Ledebur, 2007; Riss et al., 2007), people’s ability to grasp (learn) that knowledge (Chapman et al., 2007; Jashapara et al., 2006; Rosendaal, 2006). A closely related category is social capital and networking that fared much better within $\mathrm{KM}$ than in OR. The value of creating communities for KM emerges (Fahey et al., 2007; Hasan et al., 2007; Usoro et al., 2007) as a crucial player in today’s KM view. Interestingly, technological dimensions were not neglected by the KMRP community; this supports the notion that technology has a major role in delivering KM relying on the supportive capabilities provided by technology systems (Arnaert et al., 2005; Evangelou et al., 2005; Ruikar et al., 2007; Schwartz, 2007). Performance has received attention on a different approach using auditing and assessment methodologies (Alstete, 2007; Dattero et al., 2007), rather different from what previous OR performance measures would look like. Thus it is clear that there is a difference in emphasis in the subject matter of KM papers appearing in KMRP and in other journals within the OR community.

\section{KM processes:}

Figures 5(a) and 5(b) depict the Knowledge Management processes studied in the two communities. While KMRP scored high on sharing and creation, the wider OR community scored high on knowledge transfer and acquisition. This is consistent with previous noticeable trends as KMRP has placed more attention on culture, leadership, and organisational learning, along with social capital and networking, both of which can be seen as vehicles for knowledge sharing and creation using the road of 
technology (Ciabuschi, 2005; Cress et al., 2006; Usoro et al., 2007). While OR has followed up on their assumptions about knowledge being an object that can be acquired and transferred (Chua et al., 2008; Setiono et al., 2006).

In summary, despite the recent history of KM showing a stronger presence of OR related activity, OR contribution to KM is still relatively modest with only 322 articles from the 6681 papers initially found. Post-2003 KM OR publications are averaging at 38 publications per year with a very healthy increasing trend. We believe that this trend can continue for there are many future directions which OR is uniquely placed to capitalise upon e.g. risk management; personal KM including methods for individual decision making; reinterpreting KM in several ways including its interaction with decision support, complexity and community OR. We now discuss these areas for future research.

\section{The Future}

In this section we identify what we believe are the most potentially fruitful areas for "KM with an OR flavour" in the future.

\section{Risk management}

The area of risk management is attracting increased attention across many management disciplines. The risks may be financial, safety, security, project, technological or economic, to name just a few types. Since knowledge has a crucial part to play in the avoidance or mitigation of risk, the potential benefits of a closer alignment between knowledge management and risk management are clear. However, academic (or even practical) disciplines can be just as guilty of a "silo mentality" as are departments in a business, and the demarcations around some topics within risk management are very sharp indeed. Financial risk management, medical risk management and nuclear risk management have all traditionally tended to work very much within their own self-referential world.

However, the context of this decision-making has changed in the $21^{\text {st }}$ century, because of the influence of public opinion. For example, the public reaction to various financial scandals, starting with that of Enron, has led to changes in the way that financial management is carried out and reported, and this greater openness also means that there is a greater opportunity for combating disciplinary insularity. Similarly, attitudes to security were changed forever by the events of 9/11.

What is evident in most of the areas is that it is not enough to address risk management solely from a "scientific" or technological viewpoint, for example based on financial theories of credit risk. It is also necessary to include social perceptions of risk as well. This is where OR, with its ability to combine hard and soft approaches, can continue to make a contribution, e.g. in project risk (Ackermann et al., 1997). Indeed, financial risk management ought to be particularly fertile ground, since the contributions of OR in models for credit scoring have already been considerable: see for example Thomas et al (2002).

Not that this will be easy: recognising the need for broader approaches is one thing, but actually implementing them to everyone's satisfaction is quite another. The 
contribution of KM to financial risk management was being advocated as early as 1996 by one of the pioneers of KM, Larry Prusak (Marshall et al., 1996), but progress has been very slow since then (Rodriguez et al., 2007).

\section{Personal KM}

Most theorising about knowledge management (KM) has been at the organisation level. However the first decade of KM practice has shown that social, cultural and political factors usually inhibit organisations' efforts to 'manage' the knowledge of their members. This evidence may have borne out many critics' claims that the notion of knowledge management by organisations and their managers is an oxymoron, and that the only sensible way to conceive of knowledge management is at the individual level. Thus the attention of academics and practitioners is turning to Personal Knowledge Management (PKM), that is, how do we, as individuals, manage our personal knowledge, and what tools, techniques and models can be developed to enhance our personal effectiveness and improve our lives as 'knowledge workers' in today's information society.

OR people are well-equipped to contribute here, because of OR's long history of studying how individuals make decisions and providing them with modelling techniques for this, for example cognitive mapping. Problem structuring methods of all kinds are needed for PKM, especially those that explicitly aim to represent a particular viewpoint about a human activity system. Analytic methods to help work more effectively, rather than just more efficiently, are also vital, as are techniques to deal with information overload. Although OR, like KM, has often been seen as solely having a "corporate" emphasis, there is a long history of approaches that can be used by and for individuals: see for example Rosenhead (1989).

\section{Multiple views of KM}

We are entering the third generation of $\mathrm{KM}$ - there has been too much of a backlash against the over-technologised first generation of $\mathrm{KM}$, resulting in too much attention being paid to the very soft end of the subject. There is scope for more analysis and decision support in KM, and this is of special relevance to OR. Social network analysis, a topic with a history as long as that of OR itself, seems to have been neglected by the OR community, as are many of the continuing developments in intellectual capital, or indeed measurements/evaluation of all kinds related to KM. Simulation offers possibilities but it is not the discrete event simulation that OR people will be most familiar with: see for example the work on computational modelling of organisations by Nissen and others (Nissen et al., 2008). Complexity theory, which has close associations with soft OR and systems, is moving into the mainstream, in part because of developments in KM (Snowden et al., 2007). However, there is a rather uneasy relationship between complexity and soft systems: see for example Checkland's comments about the inaccuracy of the description of SSM given by some advocates of complexity theory (Checkland et al., 2006).

In parallel with this is taking the principles of $\mathrm{KM}$ into alternative spheres - taking $\mathrm{KM}$ out of the corporate/business sphere and into other contexts, where the priority is not profit, but a more social benefit e.g. preserving heritage for future generations, 
farming knowledge sharing in third world, health provision in India, social responsibility to preserve the history of the nation which is written into some constitutions. These can benefit from KM, but where is KM here - with a few exceptions such as Hasan (2008)and work on large government institutions, everyone is looking at for-profits. The notion of community KM - cKM -where social communities preserve knowledge of their own communities through various means is becoming more typical with social networking, but there are many initiatives worldwide e.g. books on local communities and villages which have utility for generations, where KM has much to contribute. The tradition of "community OR" can offer KM considerable lessons here.

\section{Conclusion}

This paper has explored the origins of KM as an academic and practitioner discipline, arguing that the role of OR has been discrete but spread across numerous aspects of $\mathrm{KM}$. While OR may have underpinned a vast number of significant milestones, infrequently have they been explicitly labelled OR, suggesting that the slogan 'OR Inside' is the case here (i.e. OR informs the inside workings of KM but is not readily visible). For example: the algorithms which underpin many knowledge based systems and search engines ensure OR Inside; many of the OR community have been visible through organising special issues, journals and books whether or not OR has taken a prominent position; many of the key figures have been shown to have emerged from an OR background. Consequently, despite a breadth and depth of significant involvement, the modest visibility of OR means its place in the history of KM could be forgotten.

Nevertheless, the future is bright. With an increasing number of journal articles on OR and KM being published we can clearly see space for the role of OR. We believe that there are three opportunities for OR to use its extensive past to significantly develop KM. The first is on risk management where OR has a strong tradition of modelling and can productively contribute analytical methods and conceptual frameworks, merging hard and soft approaches. On personal KM, the decision making methods at the heart of OR might usefully be translated to individuals. Lastly, OR's strengths in decision support, social network analysis, complexity and community OR all may be future research trajectories. In each of these cases, OR would itself benefit from further development by being applied in this alternative domain.

More generally, OR can learn (again) the lesson which seems is often overlooked that having OR Inside may be satisfying, but does not improve the overall profile of OR. While we agree with the sentiment that having OR Inside is important, we suggest that having OR Outside is equally so, not least to improve the visibility of the discipline and ultimately ensure OR's standing in academia and practice.

\section{References}

Ackermann F, Eden C and Williams T (1997). Modeling for litigation: Mixing qualitative and quantitative approaches. INTERFACES 27: 48-65. 
Alstete J W (2007). An assessment of knowledge growth stages in organizations. Knowledge Management Research \& Practice 5: 54.

Alvesson M and Karreman D (2001). Odd couple: Making sense of the curious concept of knowledge management. Journal of Management Studies 38: 995-1018. Arnaert A and Delesie L (2005). Information visualisation: a holistic tool to discover knowledge. Case study - what video-telephone care? What elderly? Knowledge Management Research \& Practice 3: 3.

Basu A (1998). Perspectives on operations research in data and knowledge management. European Journal of Operational Research 111: 1-14.

Beckman T (1999). The current state of knowledge management. In: Leibowitz J (ed). Knowledge Management HandbookCRC Press: Boca Raton, pp 1-1 - 1-22. Bell D (1974). The Coming of Post-industrial Society: A Venture in Social Forecasting. Heinemann: London.

Blackler F (1995). Knowledge, Knowledge Work and Organizations: An Overview and Interpretation. Organization Studies 16: 1021-1046.

Blackler F, Crump N and McDonald S (2000). Organizing processes in complex activity networks. Organization 7: 277-300.

Boisot M H (1998). Knowledge assets : securing competitive advantage in the information economy. Oxford University Press: Oxford.

Brown J, Collins A and Duguid P (1989). Situated cognition and the culture of learning. Educational Researcher 18: 32-42.

Brown J S and Duguid P (1991). Organizational learning and communities-of practice: Toward a unified view of working, learning and innovation. Organization Science 2: 40-57.

Castells M (1996). The Rise of the Network Society. Blackwell: Oxford. Chapman D D, Wiessner C A, Storberg-Walker J and Hatcher T (2007). New Learning: a different way of approaching conference evaluation. Knowledge Management Research \& Practice 5: 261.

Chase R L (2007). 20072007 Global MAKE Awards Executive Summary.

The KNOW Network: Ludlow, UK.

Checkland P and Poulter J (2006). Learning for action: a short definitve account of soft systems methodology and its use for practitioners, teachers and students. John Wiley \& Sons Ltd: Chichester.

Checkland P and Scholes J (1999). Soft Systems Methodology in Action. John Wiley \& Sons: Chichester

Chen S, Duan Y, Edwards J S and Lehaney B (2006). Toward Understanding Interorganizational Knowledge Transfer Needs in SMEs: Insight from a UK Investigation. Journal of Knowledge Management 10: 6-23.

Chua A L and Pan S L (2008). Knowledge transfer and organizational learning in IS offshore sourcing. Omega-International Journal of Management Science 36: 267-281. Ciabuschi F (2005). On IT systems and knowledge sharing in MNCs: a lesson from Siemens AG. Knowledge Management Research \& Practice 3: 87-96.

Coakes E (2007). Knowledge Leadership: The Art and Science of the KnowledgeBased Organization. Knowledge Management Research \& Practice 5: 154.

Coakes E and Clarke S (eds) (2006). Encyclopedia of Communities of Practice in Information and Knowledge Management Idea Group Reference: Hershey, PA. Coakes E, Willis D, and Clarke S (eds) (2002). Knowledge Management in the SocioTechnical World: The Graffiti Continues. Springer Verlag, London. 
Cook S D N and Brown J S (1999). Bridging epistemologies: The generative dance between organizational knowledge and organizational knowing. Organization Science 10: 381-400.

Cress U and Martin S (2006). Knowledge sharing and rewards: a game-theoretical perspective. Knowledge Management Research \& Practice 4: 283.

Dattero R, Galup S D and Quan J J (2007). The knowledge audit: Meta-Matrix analysis. Knowledge Management Research \& Practice 5: 213.

Davenport T H (1993). Process Innovation: Reengineering Work through Information Technology. Harvard Business School Press.: Boston, MA:.

Davenport T H (1995). The Fad That Forgot People. Fast Company: 70-74.

Davenport T H and Short J E (1990). The New Industrial Engineering: Information Technology and Business Process Redesign. Sloan Management Review: 11-27. Drucker PF (1969). The Age of Discontinuity. Heinemann: London Eden C and Ackermann F (1998). Making Strategy: The Journey of Strategic Management. Sage: London.

Edvinsson L and Sullivan P (1996). Developing a model for managing intellectual capital. European Management Journal 14: 356-364.

Edwards JS, Hall MJ and Shaw D (2005). Proposing a systems vision of knowledge management in emergency care. $J$ Opl Res Soc 56:

Edwards J S, Handzic M, Carlsson S and Nissen M (2003). Knowledge Management Research \& Practice: Visions and Directions. Knowledge Management Research \& Practice 1: 49-60.

Evangelou C and Karacapilidis N (2005). On the interaction between humans and Knowledge Management Systems: a framework of knowledge sharing catalysts. Knowledge Management Research \& Practice 3: 253.

Fahey R, Vasconcelos A C and Ellis D (2007). The impact of rewards within communities of practice: a study of the SAP online global community. Knowledge Management Research \& Practice 5: 186.

Freeman C and Perez C (1988). Structural crises of adjustment, business cycles and investment behaviour. In: Dosi G, Freeman C, Nelson R, Silverberg G and Soete L (eds). Technical Change and Economic Theory. Pinter Publishers: London, pp 3866.

Friend J and Hickling A (2005). Planning Under Pressure: The Strategic Choice Approach. Elsevier: London. 180-192.

Gibbons M, Limoges C, Nowotny H, Schwartzman S, Scott P and Trow M (1994).

The new production of knowledge: The dynamics of science and research in contemporary societies. Sage: London.

Grant R M (1991). The resource-based theory of competitive advantage: implications for strategy formulation. California Management Review 33: 114-135.

Grant R M (1996). Toward a knowledge-based theory of the firm. Strategic

Management Journal 17: 109-122.

Grant R M (1997). The knowledge based view of the firm: Implications for management practice. Long Range Planning 30: 450-454.

Hammer M (1990). Re-engineering Work: Don't Automate, Obliterate. Harvard Business Review 68: 104-112.

Hammer M and Champy J (1993). Reengineering the Corporation. : A Manifesto for Business Revolution. Nicholas Brealey: London.

Hansen M T, Nohria N and Tierney T (1999). What's your strategy for managing knowledge? Harvard Business Review 77: 106-116. 
Hasan H (2008). Back to the future for KM: the case for sensible organisation. Knowledge Management Research \& Practice 6: 26-30.

Hasan $\mathrm{H}$ and Crawford K (2007). Knowledge mobilisation in communities through socio-technical systems. Knowledge Management Research \& Practice 5: 237. Holsapple C W (ed). (2003). Handbook on Knowledge Management. Springer-Verlag: Berlin, Heidelberg and New York.

Huber G P (1991). Organizational Learning: The Contributing Processes and the Literatures. Organization Science 2: 88-115.

Jashapara A and Tai W-C (2006). Understanding the complexity of human characteristics on e-learning systems: an integrated study of dynamic individual differences on user perceptions of ease of use. Knowledge Management Research \& Practice 4: 227.

Jyrämä A and Äyväri A (2007). Fostering learning - the role of mediators. Knowledge Management Research \& Practice 5: 117.

Klein J, Connell C and Jasimuddin S (2007). Who needs memory? the case for the Markovian organisation. Knowledge Management Research \& Practice 5: 110.

Lave J and Wenger E C (1991). Situated Learning: Legitimate Peripheral

Participation. Cambridge University Press: New York.

Ledebur S C V (2007). Optimizing knowledge transfer by new employees in companies. Knowledge Management Research \& Practice 5: 229.

Leonard-Barton D (1995). Wellsprings of knowledge: Building and sustaining the sources of innovation. Harvard Business School Press: Boston.

Machlup F (1962). The Production and Distribution of Knowledge in the United States. Princeton University Press: Princeton, NJ.

Marshall C, Prusak L and Shpilberg D (1996). Financial risk and the need for superior knowledge management. California Management Review 38: 77-\&.

Mingers J (2008). Management knowledge and knowledge management: realism and forms of truth. Knowledge Management Research \& Practice 6: 62-76.

Minsky M L (ed). (1968). Semantic information processing. MIT Press: Cambridge, MA.

Montibeller G, Shaw D and Westcombe M (2006). Using decision support systems to facilitate the social process of knowledge management. Knowl Mngt Res Pract 4:

125-137.

Morgan G (1986). Images of Organization. Sage Publications: Newbury Park, CA. Newell S, Robertson M, Scarbrough H and Swan J (2002). Managing knowledge work. Palgrave: Basingstoke.

Nissen M E, Orr R J and Levitt R E (2008). Streams of shared knowledge: computational expansion of knowledge-flow theory. Knowledge Management Research \& Practice 6: 124-140.

Nonaka I (1994). A Dynamic Theory of Organizational Knowledge Creation. Organization Science 5: 14-37.

Nonaka I and Takeuchi H (1995). The Knowledge-Creating Company, How Japanese Companies Create the Dynamics of Innovation. Oxford University Press: New York and Oxford.

Nunes M B, Annansingh F, Eaglestone B and Wakefield R (2006). Knowledge management issues in knowledge-intensive SMEs. Journal of Documentation 62: 101-119.

O’Brien F and Meadows M (2007). Developing a visioning methodology: Visioning choices for the future of operational research. J Opl Res Soc 58: 557-575. 
Panagiotidis P and Edwards J S (2001). Organisational learning - a critical systems thinking discipline. European Journal of Information Systems 10: 135-146.

Pidd M (2003). Tools For Thinking: Modelling in Management Science. John Wiley \& Sons Ltd: Chichester, England.

Quintas P (2002). Managing knowledge in a new century. In: Little S, Quintas P and Ray T (eds). Managing knowledge: An essential readerSage: London, pp 1-14. Quintas P, Lefrere P and Jones G (1997). Knowledge management: A strategic agenda. Long Range Planning 30: 385-391.

Riss U V, Cress U, Kimmerle J and Martin S (2007). Knowledge transfer by sharing task templates: two approaches and their psychological requirements. Knowledge Management Research \& Practice 5: 287.

Ritchey T (2006). Problem structuring using computer-aided morphological analysis. J Opns Res Soc 57: 792-801.

Rodriguez E and Edwards J S (2007). Knowledge management applied to enterprise risk management: Is there any value in using KM for ERM? In Martins B (ed). The 8th European Conference on Knowledge Management, Vol. 2: 813-819. Academic Conferences International, Reading: Barcelona, Spain.

Roos J and Von Krogh G (1996). The epistemological challenge: Managing knowledge and intellectual capital. European Management Journal 14: 333-337. Rosendaal B (2006). Learning cycles in knowledge-intensive organisations: an exploratory study of the nature and dimensions of knowledge development in four departments. Knowledge Management Research \& Practice 4: 261.

Rosenhead J (1989). Rational Analysis for a Problematic World: Problem Structuring Methods for Complexity, Uncertainty and Conflict. John Wiley \& Sons: Chichester. Rosenhead J and Mingers J (2001). Rational Analysis for $a$ Problematic World Revisited. John Wiley \& Sons: Chichester. Ruikar K, Anumba C J and Egbu C (2007). Integrated use of technologies and techniques for construction knowledge management. Knowledge Management Research \& Practice 5: 297.

Scarbrough H and Swan J (2001). Explaining the diffusion of knowledge management: the role of fashion. British Journal of Management 12: 3-12. Schön D A (1995). The reflective practitioner: How professionals think in action. Arena: Aldershot [England].

Schwartz D G (2007). Integrating knowledge transfer and computer-mediated communication: categorizing barriers and possible responses. Knowledge Management Research \& Practice 5: 249.

Senge P M (1990). The fifth discipline, the art and practice of the learning organization. Doubleday: New York.

Setiono R, Pan S L, Hsieh M H and Azcarraga A (2006). Knowledge acquisition and revision using neural networks: an application to a cross-national study of brand image perception. Journal of the Operational Research Society 57: 231-240. Shadbolt N and Milton N (1999). From knowledge engineering to knowledge management. British Journal of Management 10: 309-322.

Shaw D and Edwards JS (2005). Building user commitment to implementing a knowledge management strategy. Inform Mngt 42: 977-988.

Simon H A (1969). The Sciences of the Artificial (1st ed.). MIT Press,: Cambridge, MA.

Snowden D J and Boone M E (2007). A Leader's Framework for Decision Making. Harvard Business Review 85: 68-76. 
Sparrow J (2005). Classification of different knowledge management development approaches of SMEs. Knowledge Management Research \& Practice 3: 136.

Spender J C (1996). Making knowledge the basis of a dynamic theory of the firm. Strategic Management Journal 17: 45-62.

Starbuck W (1992). Learning by knowledge-intensive firms. J Mngt Stud 29: 713740 .

Sutton DC (2001). What is knowledge and can it be managed? Eur J Inform Syst 10: 80-88.

Sveiby K (1996). Transfer of knowledge and the information processing professions. European Management Journal 14: 379-388.

Sveiby K and Lloyd T (1987). Managing know-how. Bloomsbury: London.

Swan J (1999). Introduction. In: Scarborough H and Swan J (eds). Case studies in knowledge managementInstitute of Personnel and Development: London, pp 1-12. Swan J, Newell S, Scarborough H and Hislop D (1999). Knowledge management and innovation: Networks and networking. Journal of Knowledge Management 3: 262275.

Thomas L C, Edelman D B and Crook J N (2002). Credit Scoring and Its Applications. Society for Industrial and Applied Mathematics: Philadelphia, PA. Usoro A, Sharratt M W, Tsui E and Shekhar S (2007). Trust as an antecedent to knowledge sharing in virtual communities of practice. Knowledge Management Research \& Practice 5: 199.

Von Krogh G (1998). Care in knowledge creation. California Management Review 40: $133-153$.

Wenger E C (1998). Communities of practice: Learning, meaning and identity. Cambridge University Press: Cambridge.

Wiig K M (1990). Expert Systems: A manager's guide. International Labour Office: Geneva.

Wiig K M (1997a). Integrating intellectual capital and knowledge management. Long Range Planning 30: 399-405.

Wiig K M (1997b). Knowledge management: Where did it come from and where will it go? Expert Systems with Applications 13: 1-14. 
Figure and Table captions

Figure 1: Knowledge management life-cycle

Figure 2: Number of published KM articles in OR journals 1990-2007

Figure 3: Categorisation of KM articles in OR journals

Figure 4: categorisation of articles in KMRP

Figure 5 (a) and (b): Further breakdown of KM process articles

Table 1: Top 20 Most Admired Knowledge Enterprises (in alphabetical order) 1998 and 2007

Table 2: KM “firsts" related to OR 
Figure 1

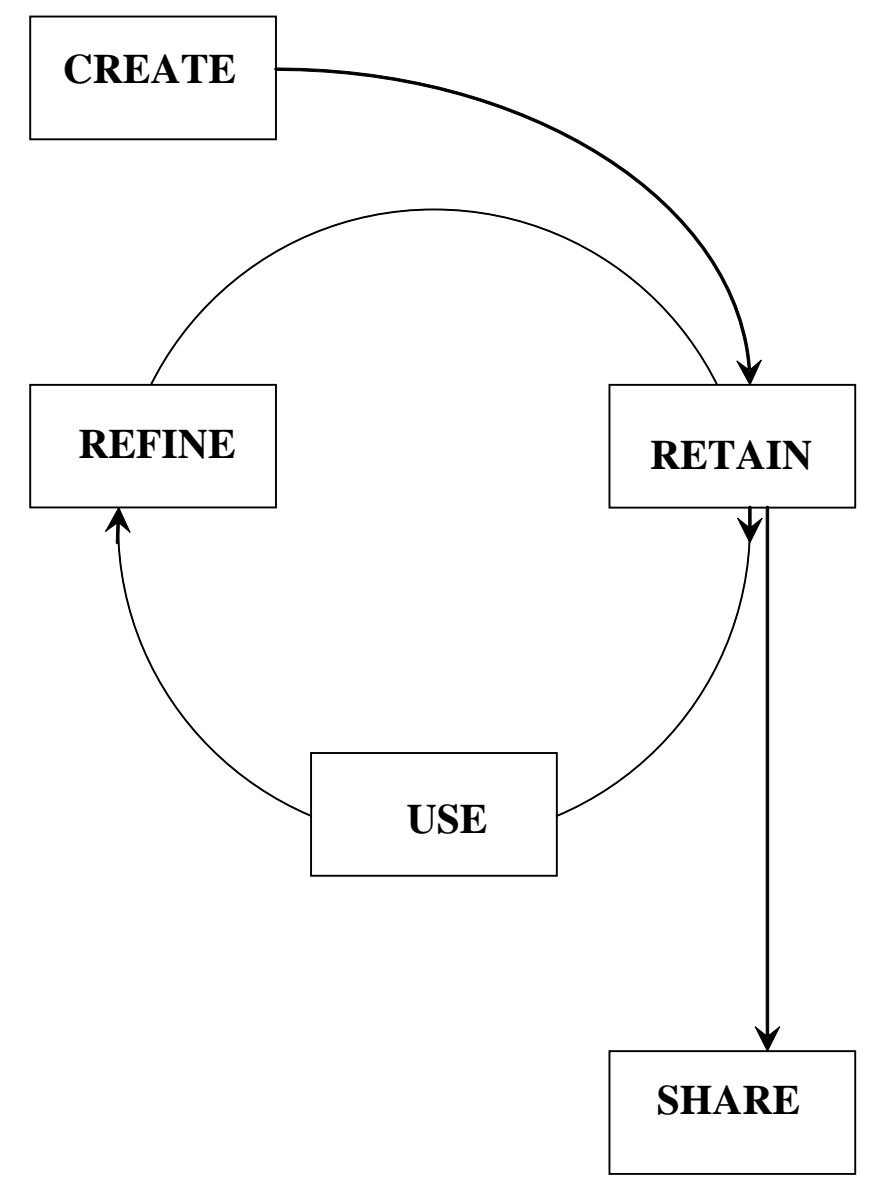


Figure 2

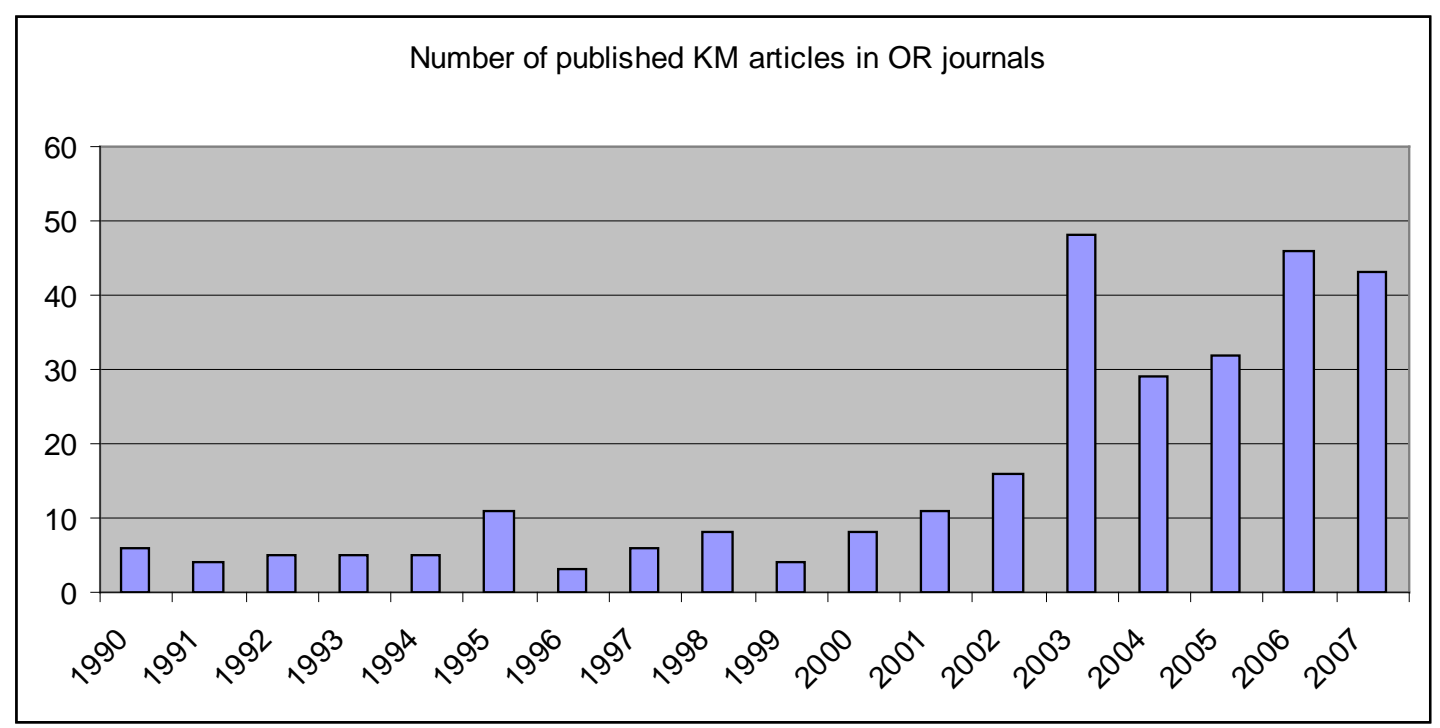


Figure 3

\begin{tabular}{|c|c|c|c|c|c|c|c|c|c|c|}
\hline \multicolumn{11}{|c|}{$\mathrm{KM}$ foci in OR journals } \\
\hline \multirow{7}{*}{ 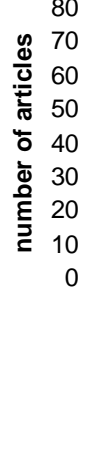 } & & & & & & & & & & \\
\hline & & & & & & & & & & \\
\hline & & & & & & & & & & \\
\hline & & & & & & & & & & \\
\hline & & & & & & & & & & \\
\hline & & & & & & & & & & \\
\hline & $\begin{array}{l}\text { Business } \\
\text { strategy, } \\
\text { compettive } \\
\text { advantage, } \\
\text { innovation }\end{array}$ & $\begin{array}{c}\text { Culture, } \\
\text { leadership, } \\
\text { organisational } \\
\text { learning }\end{array}$ & $\begin{array}{l}\text { Intellectual } \\
\text { capital }\end{array}$ & practices of $\mathrm{KM}$ & $\mathrm{KM}$ processes & $\begin{array}{l}\text { Social capital } \\
\text { and networking }\end{array}$ & Technology & $\begin{array}{l}\text { Theories about } \\
\text { knowledge }\end{array}$ & Performance & $\begin{array}{c}\text { Decision } \\
\text { making }\end{array}$ \\
\hline
\end{tabular}


Figure 4

\section{KM foci in KMRP}

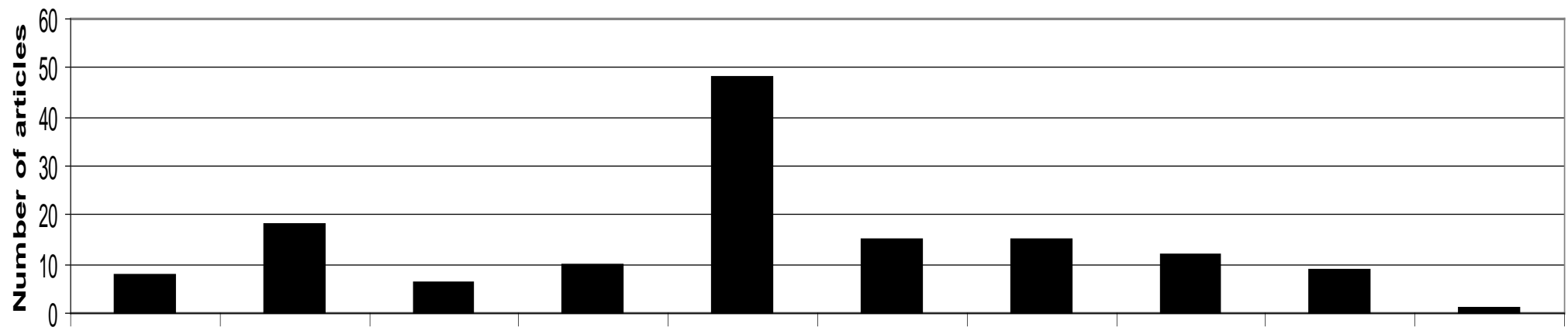

Business Culture, Intellectual practices of KM processes Social capital Technology Theories about Performance Decision strategy, leadership, capital KM and networking knowledge making compettive organisational advantage, learning innovation 
Figure 5
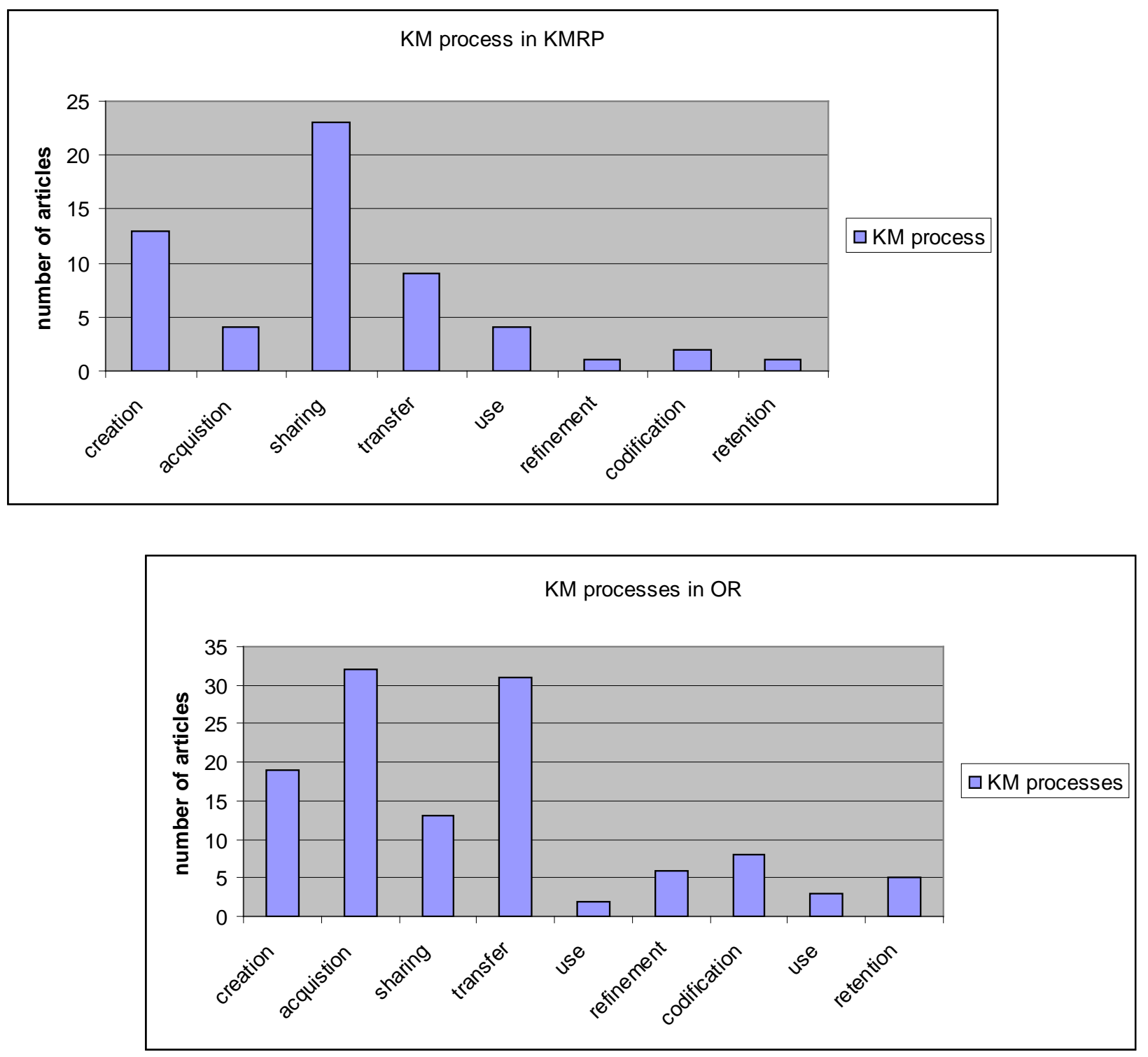
Table 1

\begin{tabular}{|l|l|}
\hline \multicolumn{1}{|c|}{1998} & \multicolumn{1}{c|}{2007} \\
\hline Andersen Consulting (USA) & Accenture (Global) \\
\hline Arthur Andersen (USA) & Apple (United States) \\
\hline BP Amoco (UK) & BP (United Kingdom) \\
\hline Buckman Laboratories (USA) & $\begin{array}{l}\text { British Broadcasting Corporation (United } \\
\text { Kingdom) }\end{array}$ \\
\hline Chevron (USA) & Ernst \& Young (Global) \\
\hline Ernst \& Young (USA) & Fluor (United States) \\
\hline General Electric (USA) & General Electric (United States) \\
\hline Hewlett-Packard (USA) & Google (United States) \\
\hline IBM (USA) & IBM (United States) \\
\hline Intel (USA) & Infosys Technologies (India) \\
\hline Lucent Technologies* (USA) & Intel (United States) \\
\hline Microsoft (USA) & McKinsey \& Company* (Global) \\
\hline Monsanto (USA) & Microsoft (United States) \\
\hline Nokia (Finland) & Nokia (Finland) \\
\hline Pfizer (USA) & Royal Dutch Shell (The \\
& Netherlands/United Kingdom) \\
\hline Siemens (Germany) & Samsung Group (S. Korea) \\
\hline Skandia (Sweden) & 3M (United States) \\
\hline Sun Microsystems (USA) & Toyota (Japan) \\
\hline 3M (USA) & Wikipedia (Global) \\
\hline Xerox (USA) & Wipro Technologies (India) \\
\hline
\end{tabular}

(* = overall winner) 
Table 2

\begin{tabular}{|l|l|}
\hline $\begin{array}{l}\text { First KM paper in an OR/MS journal } \\
\text { (Basu, 1998) }\end{array}$ & November 1998 \\
\hline $\begin{array}{l}\text { First Knowledge Management Aston } \\
\text { Conference }\end{array}$ & July 2000 \\
\hline $\begin{array}{l}\text { Triple stream on Learning Organisations } \\
\text { and Knowledge Management at UK OR } \\
\text { Society Annual Conference (OR42) }\end{array}$ & September 2000 \\
\hline Special Issue of EJIS & June 2001 \\
\hline $\begin{array}{l}\text { Tutorial on Knowledge \& Knowledge } \\
\text { Management at INFORMS annual } \\
\text { meeting, Miami Beach }\end{array}$ & November 2001 \\
\hline Special Issue of Organization Science & May-June 2002 \\
\hline $\begin{array}{l}\text { Stream on KM and Intellectual Capital at } \\
\text { IFORS }\end{array}$ & July 2002 \\
\hline $\begin{array}{l}\text { First KM encyclopaedia (Holsapple, } \\
\text { 2003) }\end{array}$ & December 2002 (sic) \\
\hline Special Issue of JORS & February 2003 \\
\hline Special Issue of Management Science & April 2003 \\
\hline Stream at EURO XIX, Istanbul & July 2003 \\
\hline $\begin{array}{l}\text { First issue of Knowledge Management } \\
\text { Research \& Practice }\end{array}$ & July 2003 \\
\hline
\end{tabular}

